\title{
Idosos dependentes: famílias e cuidadores
}

\author{
Dependent seniors: families and caregivers
}

Ursula M. Karsch 1

\footnotetext{
1 Pontifícia Universidade Católica de São Paulo. Rua Monte Alegre 984, São Paulo, SP 05014-901, Brasil. ulakar@uol.com.br
}

\begin{abstract}
This article focuses on health care for dependent seniors in relation to chronic illnesses. Expectations about family support for the dependent elderly are related to the role of family caregivers, but care requires support from the public and private sectors. Governments throughout the developed countries are examining their role in the provision of social welfare programs, especially in the public health sector. To recommend home care and family assistance, the context of changing family structures, the type of care needed, and professional follow-up must be taken into account.
\end{abstract}

Key words Aging Health; Home Nursing; Caregivers

Resumo Este artigo centra-se no tema assistência a idosos dependentes por doença crônica e degenerativa, e chama a atenção para o papel do cuidador em casa. A recomendação para que os cuidados aos idosos dependentes sejam desenvolvidos no domicílio está ganhando mais força, muitas vezes de maneira incauta por parte dos profissionais de saúde. Delegar à família a função de cuidar necessita de clareza sobre a estrutura familiar, o tipo de cuidado a ser executado, o tempo necessário, as características da doença e o acompanhamento profissional. Em países onde o envelhecimento populacional se deu mais lentamente do que no Brasil, os cuidados e os cuidadores familiares são objeto de políticas e programas de Saúde Pública.

Palavras-chave Saúde do Idoso; Cuidados Domiciliares de Saúde; Cuidadores 
A freqüência das doenças crônicas e a longevidade atual dos brasileiros são as duas principais causas do crescimento das taxas de idosos portadores de incapacidades. A prevenção das doenças crônicas e degenerativas, a assistência à saúde dos idosos dependentes e o suporte aos cuidadores familiares representam novos desafios para o sistema de saúde instalado no Brasil.

Neste país, a velhice sem independência e autonomia ainda faz parte de uma face oculta da opinião pública, porque vem sendo mantida no âmbito familiar dos domicílios ou nas instituições asilares, impedindo qualquer visibilidade e, conseqüentemente, qualquer preocupação política de proteção social.

Estudos revelam que cerca de $40 \%$ dos indivíduos com 65 anos ou mais de idade precisam de algum tipo de ajuda para realizar pelo menos uma tarefa como fazer compras, cuidar das finanças, preparar refeições e limpar a casa. Uma parcela menor (10\%) requer auxílio para realizar tarefas básicas, como tomar banho, vestir-se, ir ao banheiro, alimentar-se, sentar e levantar de cadeiras e camas, segundo Medina (1998). Estes dados remetem à preocupação por mais de 6 milhões de pessoas e famílias, e a um e meio milhão de idosos gravemente fragilizados no Brasil, segundo a Pesquisa Nacional por Amostra de Domicílios (PNAD) de 2001 (IBGE, 2002).

Historicamente, diferentes países do mundo têm desenvolvido variadas formas de apoio e cuidados aos seus idosos dependentes, e, em alguns países, o suporte oferecido é quase exclusivamente de responsabilidade estatal, em outros, são predominantemente as famílias que desempenham todos os encargos. Em alguns países, ainda, as responsabilidades são divididas, em graduações variadas, entre o setor público e o privado, incluindo benefícios, políticas e serviços previdenciários, de organizações sindicais, de empresas para seus funcionários responsáveis por algum idoso dependente, de agências e unidades sanitárias estatais, assim como de organizações particulares de segurosaúde, conforme o estudo comparativo entre onze países, de Lechner \& Neal (1999).

Entretanto, estes diferentes modelos estão sofrendo novos impactos e mudanças inusitadas causados pelas transformações nas relações sociais, sejam no âmbito do trabalho e emprego, sejam nas estruturas familiares, ou até no redirecionamento das funções de proteção e justiça social do Estado, de acordo com o que discutem os estudos do Núcleo de Estudos e Pesquisas em Seguridade e Assistência Social da Pontifícia Universidade Católica de São Pau- lo (PUC-SP) (Sposati et al., 2002). Os governos dos países desenvolvidos estão avaliando o seu papel na provisão de políticas de bem-estar social, e a tendência à redução dos investimentos nos setores de saúde e de benefícios reverte na ampliação das responsabilidades familiares pelo sustento e pelos cuidados aos idosos dependentes e incapacitados.

No Brasil, a transição demográfica e a transição epidemiológica apresentam, cada vez mais, um quadro de sobrevivência de idosos na dependência de uma ou mais pessoas que suprem as suas incapacidades para a realização das atividades de vida diária. Estas pessoas são familiares dos idosos, especialmente, mulheres, que, geralmente, residem no mesmo domicílio e se tornam as cuidadoras de seus maridos, pais e até mesmo filhos. Aliás, não é só no Brasil que as mulheres são as "grandes cuidadoras" dos idosos incapacitados: todos os autores e os dados coletados pelo mundo indicam que, salvo por razões culturais muito específicas, a mulher é a cuidadora tradicional (Kinsella \& Taeuber, 1992). Por causas predominantemente culturais, o papel da mulher cuidadora, no Brasil, ainda é uma atribuição esperada pela sociedade (Neri, 1993). A visibilidade social desta personagem, porém, ainda é muito restrita, sobretudo nos países em que o envelhecimento da população vem acontecendo há poucas décadas.

A literatura sobre cuidadores, em muitos países desenvolvidos, é extensa, e as tentativas de conceituar cuidadores formais e informais, ou cuidadores principais e secundários, e fatores que designam o tipo de cuidador requerido para cada idoso dependente é bastante discutido com base em dados empíricos. Nestes termos, a literatura internacional aponta para quatro fatores, geralmente presentes, na designação da pessoa que, preferencialmente, assume os cuidados pessoais ao idoso incapacitado: parentesco (cônjuges); gênero (principalmente, mulher); proximidade física (vive junto) e proximidade afetiva (conjugal, pais e filhos). A este respeito ver Sinclair (1990), Ungerson (1987), Stone et al. (1987) e Lewis \& Meredith (1988).

Por motivos vários, como a redução de custo da assistência hospitalar e institucional aos idosos incapacitados, a atual tendência, em muitos países e no Brasil, é indicar a permanência dos idosos incapacitados em suas casas sob os cuidados de sua família.

No entanto, a recomendação não tem sido objeto de debates críticos, a não ser muito recentemente. Os pressupostos, nem sempre presentes, de um modelo estável de família nuclear, e de que qualquer família pode sempre 
contar com a disponibilidade de um de seus membros para assistir às necessidades dos idosos dependentes fazem parte, sem nenhuma crítica, das propostas de serviços de assistência médica domiciliar.

É preciso e urgente que, quando se propuserem os cuidados familiares, seja examinada a estrutura familiar na sociedade e na cultura em que estes cuidados devem ser desenvolvidos.

Criado em 1991, o grupo multidisciplinar de pesquisa, Epidemiologia do Cuidador, dentro do Programa de Estudos Pós-graduados em Serviço Social da PUC-SP, tem realizado estudos cujo objetivo é o perfil do cuidador familiar no Brasil. O primeiro trabalho acadêmico realizado entre 1992 e 1997 denomina-se Estudo do Suporte Domiciliar aos Adultos com Perda de Independência e Perfil do Cuidador Principal, com o apoio do Dr. Alexandre Kalache, na época, na London School of Hygiene \& Tropical Medicine, e cujos resultados foram publicados pela Editora da PUC-SP (Karsch, 1998). Este estudo, levado a efeito no Município de São Paulo, revelou quem são os cuidadores principais nos domicílios de 102 pessoas com mais de 50 anos, que sofreram o primeiro episódio de acidente vascular cerebral (AVCs), e retornaram às suas casas apresentando um quadro de dependência de outra pessoa para a realização das suas atividades de vida diária. Tais vítimas do AVC, que depois de um ano continuaram incapacitados, provavelmente envelhecerão na dependência de um cuidador. $\mathrm{O}$ estudo mostrou que o impacto nas relações familiares, causado pelo primeiro ou por múltiplos AVC e suas conseqüências, mostrou-se muito forte. Decorrente das alterações inevitáveis, que envolvem afeto, finanças, relações de poder e outras variáveis, desenvolveu-se um processo de reorganização familiar, quando alguém deixava de executar tarefas pessoais, domésticas e sociais. A perda de independência, e às vezes até da autonomia de um idoso, pressupõe que, em casa, alguém assuma as funções de cuidador. Tratase da pessoa que chama a si a incumbência de realizar as tarefas para as quais o doente lesado pelo episódio mórbido não tem mais possibilidade; tarefas que vão desde a higiene pessoal até a administração financeira da família.

Em 98\% dos casos pesquisados, o cuidador era alguém da família, predominantemente do sexo feminino $(92,9 \%)$. A maior parte era formada de esposas $(44,1 \%)$, seguidas pelas filhas $(31,3 \%)$; as noras e as irmãs não foram freqüentes. $\mathrm{O}$ cuidador familiar revelou-se o ator social principal na dinâmica dos cuidados pessoais necessários às atividades de vida diária dos portadores de lesões que lhe tiraram a inde- pendência; contudo, 67,9\% dos cuidadores entrevistados prestavam estes cuidados sem nenhum tipo de ajuda. A faixa etária de $59 \%$ dos cuidadores estava acima de 50 anos e $41 \%$ tinham mais de 60 anos. Os dados mostraram, também, que 39,3\% de cuidadores, entre 60 e 80 anos, cuidavam de $62,5 \%$ de pacientes da mesma faixa etária, o que mostra que pessoas idosas estão cuidando de idosos. As condições físicas desses cuidadores levaram a inferir que os cuidadores são doentes em potencial e que sua capacidade funcional está constantemente em risco. Os dados sobre a saúde dos cuidadores reforçam essa hipótese: dos casos entrevistados, 40,7\% tinham dores lombares, 39,0\%, depressão, 37,3\% sofriam de pressão alta, 37,3\% tinham artrite e reumatismo, $10,2 \%$, problemas cardíacos, e 5,1\%, diabete.

Apesar das mudanças ocorridas no cenário nacional em relação às políticas de proteção social ao idoso, estas ainda se apresentam muito restritas na oferta de serviços e programas de Saúde Pública, como na amplitude da sua intervenção. O Estado se apresenta como um parceiro pontual, com responsabilidades reduzidas, que atribui à família a responsabilidade maior dos cuidados desenvolvidos em casa a um idoso na dependência de outra pessoa. Constata-se que inexiste uma política mais veemente no que se refere aos papéis atribuídos às famílias e aos apoios que cabem a uma rede de serviços oferecer ao idoso dependente e aos seus familiares.

Cuidar do idoso em casa é, com certeza, uma situação que deve ser preservada e estimulada; todavia, cuidar de um indivíduo idoso e incapacitado durante 24 horas sem pausa não é tarefa para uma mulher sozinha, geralmente com mais de 50 anos, sem apoios nem serviços que possam atender às suas necessidades, e sem uma política de proteção para o desempenho deste papel. Em países mais desenvolvidos, em que o envelhecimento populacional foi mais lento e recebeu mais atenção durante décadas, foi construída uma rede de organizações maiores e menores, que se define como community care, e cujo grande objetivo é manter o idoso em sua casa oferecendo suportes para a família e o cuidador. Entre as diferentes modalidades de assistência ao cuidador, destaca-se o serviço de sua substituição por um profissional, para alternar os cuidados com alguém. Outro programa fundamental para idosos, que existe em muitos países, é "comida sobre rodas", que produz e distribui as refeições programadas para os doentes e incapacitados, poupando o cuidador da tarefa de cozinhar todos os dias. 
O cuidador familiar de idosos incapacitados precisa ser alvo de orientação de como proceder nas situações mais difíceis, e receber em casa periódicas visitas de profissionais, médico, pessoal de enfermagem, de fisioterapia e outras modalidades de supervisão e capacitação. Este apoio é fundamental quando se trata de um casal de idosos, em que o cônjuge menos lesado assume os cuidados do outro, que foi acometido por uma súbita e grave doença incapacitante.

É preciso, também, chamar a atenção dos profissionais de saúde que indicam cuidados em casa a idosos dependentes, que sejam consideradas as mudanças sociais e econômicas que estão transformando as estruturas familiares nas cidades brasileiras e como estas podem afetar a posição e o papel tradicional do cuidador de idosos fragilizados e dependentes.

Até pouco tempo atrás, a família era entendida como o conjunto de pessoas residentes sob o mesmo teto, e, que, entre si, apresentam laços de parentesco e de afinidade. Estas características, entretanto, têm sofrido alterações de todos os tipos, e há sempre quem afirme que "a família está em crise”, conforme Sullerot (1997).

As estruturas familiares, no mundo inteiro, estão sofrendo modificações rápidas ocasionadas por diferenciados motivos: separações; divórcios e novas uniões; instabilidade do mercado de trabalho e movimentos migratórios nacionais e internacionais em busca de oportunidades de trabalho; maior tempo de vida das gerações e um aumento do contingente de viúvas, geralmente morando sozinhas nas cidades; idosos exercendo chefias de família; e a participação crescente da mulher no mercado de trabalho.

Nas últimas décadas, no Brasil, vem sendo notado o aumento do número de separações e divórcios, tanto entre casais mais antigos como entre cônjuges com pouco tempo de vida conjugal. Registrou-se, a cada uma das três últimas décadas, o dobro de separações e divórcios da década anterior (IBGE, 1993). A freqüência de idosos divorciados neste início de século será muito mais alta do que em qualquer outra geração precedente.

Se o fracasso do primeiro casamento for seguido de uma nova união, e se desta nascerem filhos, ou se os filhos de dois ou mais casamentos passarem a morar na mesma casa, a estrutura familiar torna-se mais complexa, e novos laços afetivos podem se formar, assim como novas rupturas podem abalar as relações familiares. É provável que, mais tarde, esta alteração reflita na identificação do cuidador e da or- ganização dos cuidados aos idosos residentes na casa.

Na década de 90, o desemprego e o trabalho informal afetaram mais de 40 milhões de pessoas no mundo. De um lado o mercado informal não oferece segurança nem possibilidade de aposentadoria, de outro, a tecnologia vem substituindo a mão de obra, fazendo os salários caírem e a taxa de desemprego aumentar. Esta realidade desencadeia uma onda migratória permanente dos mais jovens e mais corajosos, que largam as suas famílias e ingressam em algum mercado de trabalho em outra cidade ou em outro país. Hoje não é difícil em qualquer país estrangeiro ouvir conversas de brasileiros atrás de balcões de lojas em Portugal, ou servindo em bares e restaurantes americanos, espanhóis, franceses ou japoneses. Nem sempre há a expectativa de retorno. E assim, no Brasil, muitas pessoas sabem que vão envelhecer sem a perspectiva de receber qualquer apoio de seus filhos. Há casos em que o avô ou a avó ficam encarregados de tomar conta dos netos; e quando algum dos velhos adoece, quem vai cuidar é, muitas vezes, uma criança ou um adolescente, sem qualquer experiência para desempenhar o papel de cuidador (Medeiros, 1998).

A longevidade e a diminuição do número de nascimentos nas cidades brasileiras está "verticalizando" as estruturas familiares, e uma nova forma de convívio está aparecendo: a "intimidade à distância”, segundo a qual as pessoas não moram na mesma casa, mas se visitam, telefonam e trocam favores, conforme afirma Birren (1998). Como fica este convívio à distancia no momento em que um idoso da família se torna dependente?

Mesmo morando com os seus pais, a atual geração de mulheres integra desde cedo o mercado de trabalho. Para as mais jovens a vida profissional representa as fundações de seu futuro, em torno do qual irão organizar, como puderem, os futuros acontecimentos familiares. Em alguns países, como nos Estados Unidos, existe uma política de apoio a estas mulheres no caso de algum idoso delas vier a depender. Podem ter reduzida a sua jornada de trabalho e receber uma ajuda em dinheiro para suprir os gastos com a assistência prestada ao seu idoso, como citado em Lechner \& Neal (1999).

É sabido que as mulheres, em quase todo o mundo, vivem, em média, mais do que os homens. No Brasil esta diferença corresponde, hoje, a mais de sete anos. A razão de sexos para a população idosa brasileira, em 1991, era de 100 mulheres para cada 83 homens de mais de 65 anos, conforme Berquó (1996). Este dado 
torna visível o reforço gradual do contingente de viúvas na sociedade brasileira; muitas delas estão desempenhando o papel de chefe de família. Mas é às chefias femininas que correspondem os menores rendimentos. O Censo Demográfico de 1991 já apresentou mais de 1,4 milhões de domicílios chefiados por mulheres com mais de 65 anos, das quais 1,1 milhões na classe de rendimento de até dois salários mínimos! O mesmo censo contou 2,8 milhões de homens chefes de família com mais de 65 anos, e pouco mais de 2 milhões com o mesmo rendimento (IBGE, 2002).

A transição demográfica no Brasil exige novas estratégias para fazer frente ao aumento exponencial do número de idosos potencialmente dependentes, com baixo nível sócio-econômico, consumidores de uma parcela desproporcional de recursos da saúde destinada ao financiamento de leitos de longa permanência.

A internação dos idosos em asilos, casas de repouso e similares, está sendo posta em questão até nos países desenvolvidos, onde estes serviços alcançaram níveis altamente sofisticados de conforto e eficiência. O custo desse modelo e as dificuldades de sua manutenção estão requerendo medidas mais resolutivas e menos onerosas. No Brasil é comum, mesmo nas famílias de renda geral mensal abaixo de dois salários mínimos, que a opção de internar o seu idoso em instituições asilares ocorra, predominantemente, no limite da capacidade familiar em oferecer os cuidados necessários. Com todas as dificuldades, os cuidadores dos idosos dependentes das famílias visitadas durante a pesquisa sobre o suporte domiciliar referiram que, se pudessem manter o seu velho em casa, o fariam até o último minuto (Karsch, 1998).

Dessa maneira, o envelhecimento com dependência toma significados particulares que, dentro de um contexto histórico, social, político, econômico e cultural, precisa ser analisado e esclarecido. Na metrópole brasileira, cenário em que se concentra o envelhecimento saudável, também se acumula o envelhecimento em dependência.

Tanto nos Estados Unidos, como na Europa, há grandes investimentos das políticas públicas a fim de construir e manter redes de suporte a idosos, ou diretamente, ou prestando apoio a cuidadores: familiares, voluntários e profissionais. Isto é conhecido porque pesquisas recentes, como as de Lechner \& Neal (1999), mostram que os cuidados oriundos de redes informais de apoio constituem a mais importante fonte de suporte a idosos e, por isso mesmo, precisam ser estudados e amparados.

Pode-se inferir, portanto, que o envelhecimento em dependência e a figura do cuidador estão a exigir novas formas de assistência e novos enfoques por parte das políticas públicas de saúde. Além do que, o próprio envelhecimento da população brasileira está se dando num momento de profunda desordem econômica, deixando, com certeza, a população de baixa renda mais desamparada e carente, demandando posturas de apoios compensatórios a essa realidade. Está se configurando um severo e crítico quadro de exclusão social do idoso, tanto mais grave, quando esse idoso perder a sua capacidade funcional. 


\section{Referências}

BERQUÓ, E., 1996. Algumas considerações demográficas sobre o envelhecimento da população no Brasil. In: I Seminário Internacional Envelhecimento Populacional, Anais, p. 22, Brasília: Secretaria da Assistência Social, Ministério da Previdência e Assistência Social.

BIRREN, J. E., 1998. A psychological perspective on the challenges of an aging society. In: Aging Populations: The Challenge of an Aging Society, Proceedings, p. 357, Salzburg: Draft.

IBGE (Fundação Instituto Brasileiro de Geografia e Estatística), 1993. Anuário Estatístico do Brasil. Rio de Janeiro: Secretaria de Planejamento, Orçamento e Coordenação.

IBGE (Fundação Instituto Brasileiro de Geografia e Estatística), 2002. Dados sobre População do Brasil, PNAD (Pesquisa Nacional por Amostra de Domicílios) 2001. 27 Julho $2002<$ http://www.ibge. gov.br>.

KARSCH, U. (org.), 1998. Envelhecimento com Dependência: Revelando Cuidadores. São Paulo: EDUC.

KINSELLA, K. \& TAEUBER, C. M., 1992. An Aging World II. Washington, DC: U.S. Government Printing Office.

LEWIS, J. \& MEREDITH, B., 1988. Daughters Who Care: Daughters Caring for Mothers at Home. London: Routledge.

LECHNER, V. \& NEAL, M., 1999. The mix of public and private programs in the United States: Implications for employed caregivers. In: Work and Caring for the Elderly: International Perspectives (S. V. Lechner \& M. Neal, org.), pp. 120-137, Philadelphia: Taylor \& Francis.
MEDEIROS, M., 1998. Impacto da Doença e Qualidade de Vida dos Cuidadores Primários de Pacientes com Artrite Reumatóide: Adaptação Cultural e Validação do Caregiver Burden Scale. Tese de Doutorado, São Paulo: Universidade Federal de São Paulo.

MEDINA, C.; SHIRASSU, M. \& GOLDFEDER, M., 1998. Das incapacidades e do acidente cerebrovascular. In: Envelhecimento com Dependência: Revelando Cuidadores (U. Karsch, org.), pp. 199214, São Paulo: EDUC.

NERI, A. L., 1993. Qualidade de Vida e Idade Madura. Campinas: Papirus.

SPOSATI, A. (org.), 2002. Benefício de prestação continuada e assistência social como política de garantia de renda. In: Seminário Internacional: Mínimos de Cidadania e Benefícios a Idosos e Pessoas Deficientes: Brasil, França e Portugal, Anais, pp. 6-28, São Paulo: Pontifícia Universidade Católica de São Paulo/Fundação de Amparo a Pesquisa do Estado de São Paulo.

SINCLAIR, I., 1990. Carers: Their Contribution and Quality of Life in the Kaleidoscope of Care. London: National Institute for Social Work.

STONE, R.; CAFFERATA, G. \& SANGL, J., 1987. Caregivers of the frail elderly: A national profile. Gerontologist, 27:616-626.

SULLEROT, E., 1997. A Família. Da Crise à Necessidade. Lisboa: Tipografia Peres.

UNGERSON, C., 1987. Policy is Personal: Sex Gender and Informal Care: Tovistock. London: Tovistock.

Recebido em 29 de abril de 2002

Versão final reapresentada em 17 de outubro de 2002 Aprovado em 21 de fevereiro de 2003 